\title{
ПРОГНОСТИЧЕСКОЕ ЗНАЧЕНИЕ ДИСФУНКЦИИ ЭНДОТЕЛИЯ И МИОКАРДИАЛЬНОГО ФИБРОЗА У ПАЦИЕНТОВ С ХРОНИЧЕСКОЙ СЕРДЕЧНОЙ
} НЕДОСТАТОЧНОСТЬЮ, ПЕРЕНЕСШИХ ИНФАРКТ МИОКАРДА

\section{PROGNOSTIC VALUE OF ENDOTHELIAL DYSFUNCTION AND MYOCARDIAL FIBROSIS IN PATIENTS WITH CHRONIC HEART FAILURE WHO HAVE SUFFERED A MYOCARDIAL INFARCTION}

Yu. Trusov

A. Zinkina

Summary. Chronic heart failure is a serious and complex disease that can significantly complicate a person's life or even put it at risk, especially for patients who have already suffered a myocardial infarction. For the possibility of effective maintenance therapy, it is a significant and urgent issue to identify the prognostic significance of the underlying factors of this disease. The article considers the essence of endothelial dysfunction and its prognostic value, as well as myocardial fibrosis. A study of the prognostic value of endothelial dysfunction and myocardial fibrosis was conducted, correct methods for predicting these factors were determined, their significance was established in the process of determining the criteria for the course of chronic heart failure in patients who had suffered a myocardial infarction.

Keywords: endothelial dysfunction, myocardial fibrosis, chronic heart failure, myocardial infarction, prognostic value, fibrous tissue.

\section{Введение}

$\mathbf{H}$ а сегодняшний день поиск эффективных направлений диагностирования и лечения граждан с хронической сердечной недостаточностью, перенесших инфаркт миокарда является достаточно затруднительным. Это связано с тем, что данное заболевание относится к разряду неблагоприятных в плане прогностических исследований. Важнейшими факторами, устанавливающими прогноз дальнейшего течения заболевания остаются дисфункция эндотелия и миокардиальный фиброз [1].

Эндотелиальная дисфункция представляет собой патологию эндотелия, вызванную расстройством синтеза различных эндотелиальных критериев. Такое состоя-
Трусов Юрий Александрович

Аспирант, Самарский Государственный Медицинский Университет

Зинкина Анна Алексеевна

Аспирант, Самарский Государственный Медицинский Университет anna-zinkina@mail.ru

Аннотация. Хроническая сердечная недостаточность является серьёзным и сложным заболеванием, способным существенно осложнять жизнь человека или даже ставить ее под угрозу, особенно это касается пациентов, которые уже перенесли инфаркт миокарда. Для возможности проведения эффективной поддерживающей терапии значимым и актуальным вопросом является выявление прогностического значения основополагающих факторов этого заболевания. В статье рассмотрена сущность дисфункции эндотелия и ее прогностическое значение, а также миокардиальный фиброз. Проведено исследование прогностического значения дисфункции эндотелия и миокардиального фиброза, определены корректные методы прогнозирования данных факторов, установлено их значение в процессе определения критериев течения хронической сердечной недостаточности у пациентов, перенесших инфаркт миокарда.

Ключевые слова: дисфункция эндотелия, миокардиальный фиброз, хроническая сердечная недостаточность, инфаркт миокарда, прогностическое значение, фиброзная ткань.

ние эндотелия не способно поддерживать гемореологический баланс крови, нарушение которого приводит к недостаточности сердечной работы. Эндотелиальная дисфункция являет базисную основу в патогенезе большого количества заболеваний, в том числе, и сердечной недостаточности.

Формирование фиброзной ткани представляет собой естественный процесс, протекающий во всех тканях организма в течение жизнедеятельности человека. Существование хронических заболеваний существенно усугубляет его течение. Этот процесс весьма популярен при хронической сердечной недостаточности. Пациенты, перенесшие инфаркт миокарда наиболее подвержены образованию микардиального фиброза, что существенно затрудняет терапию такого заболевания. 
Особую значимость и актуальность имеет прогностическое значение вышеописанных проявлений, сопутствующих течению хронической сердечной недостаточности у пациентов, перенесших инфаркт миокарда.

\section{1. Прогностическое значение Аисфункчии энАотелия у пашиентов с хронической серАечной неАОстатОчнОстью, перенесших инфаркт миокарАа}

Эндотелиальная дисфункция представляет собой первейший сигнал о начале поражения сосудов, она прогнозируется ранее, чем это можно установить при помощи ангиографического или ультразвукового исследования состояния сосудов.

Научные работы ученых акцентируют внимание на актуальности и серьёзности прогностического значения эндотелия у пациентов с хронической сердечной недостаточностью [3].

Специфика прогнозирования дисфункции эндотелия представляет собой целый ряд направлений, при помощи исследования которых становится возможным увидеть картину заболевания человека в более развёрнутом виде, и оказать терапевтическую поддержку людям, перенёсшим инфаркт миокарда.

Эндотелиальная мембрана выкладывается по внутренней поверхности сердца и сосудов. Ее основная функция заключается в синтезе большого числа значимых для организма биологически активных веществ, исходя из этого, клетки эндотелия приравнивают к массивному паракринному органу, который в своей совокупности, распространяясь по всей поверхности тела, способен оказывать благоприятное или негативное влияние на все системы организма, именно поэтому прогностическое значение дисфункции эндотелия так велико у людей с хронической сердечной недостаточностью, перенёсших инфаркт миокарда.

Эндотелий вырабатывает вазодилататоры и антиагреганты (оксид азота (N0), брадикинин, простациклин, простагландин Е2, вазоконстрикторы и проагреганты (эндотелин-1, ангиотензин II, серотонин, простагландин F2a, лейкотриены C4, Д4, тромбоксан A2, гепарин, активаторы плазминогена, факторы роста. Его работа заключается в обеспечении сосудодвигательной функции, антитромбоцитарной, антикоагулянтной, тромболитической, противовоспалительной, антиоксидантной и антипролиферативной. Эндотелию отведена важнейшая роль в ремоделировании сосудов, своевременное прогнозирование которых у больных, перенесших инфаркт, является крайне значимым аспектом.
Эндотелий реализует барьерный процесс, обеспечивающий гомеостаз при помощи поддержания динамического равновесия нескольких разнонаправленных процессов в организме.

У людей, перенесших инфаркт миокарда, необходимо проводить прогнозирование процесса дилатации кровеносных сосудов, поэтому следует вести постоянное наблюдение за процессом выработки оксида азота, который оказывает стимулирующее влияние на рецепторы клеток эндотелия. В том числе, синтез оксида азота обеспечивает высвобождение вазоактивных медиаторов, ингибирует адгезию лейкоцитов, способствует ремоделированию сосудистой стенки, при этом происходит угнетение активности провоспалительных тел, блокировка тромбоцитов.

При острой сердечной недостаточности необходимо контролировать уровень брадикинина, который синтезируется в крови посредством воздействия ферментов калликреина, поскольку брадикинин отвечает за активацию образования оксида азота.

Главной движущей силой высвобождения оксида азота в эндотелии является давление тока крови, направленного на стенки сосудов. В случае если образуется турбулентное движение крови, то интенсивность образования оксида азота существенно снижается. Прогностическое значение данного фактора велико, поскольку гемодинамический критерий при хронической сердечной недостаточности крайне важен.

Эндотелий является источником выработки такого вазодилатирующего компонента, как простациклин, который представляет собой важный регулятор сосудистого тонуса у людей с хронической сердечной недостаточностью.

Недавние исследования ученых отображают экспериментальные и клинические разработки в части детального рассмотрения прогностического значения эндотелиальной дисфункции, а также связанного с этим процесса прогрессирования критериев хронической сердечной недостаточности.

Ряд ученых связывает факт дисфункции эндотелия с ограничением биодоступности оксида азота в крови, что крайне важно при прогностировании эндотелиальной дисфункции. К основополагающей роли дисфункции эндотелия относят окислительный стресс, синтез вазоконрикторов, в том числе цитокинов, которые отвечают за производство оксида азота. В случае, если негативные факторы действую продолжительное время, то наступает истощение и модификация функциональной способности эндотелия, что провоцирует утонче- 
ние стенок сосудов и возможность образования тромбов [2].

Когда эндотелий функционирует нормально, то базальный синтез оксида азота производится планомерно и постоянно. Данный фактор обеспечивает нормальный тонус сосудов.

Оксид азота имеет антиоксидантное свойство, в том числе, ингибирует агрегацию и адгезию тромбоцитов. Оксид азота представляет собой активный, ангиопротективный компонент.

На сегодняшний день доказанным фактором благополучной терапии хронической сердечной недостаточности считается регуляция дилатации и адгезии тромбоцитов. Следовательно, нормальный баланс эндотелиальной функции возможно рассматривать как баланс противоположно действующих факторов.

Вазодилатирующее свойство эндотелия реализует совокупность критериев релаксации оксида азота, простациклина и эндотелиального гиперполяризирующего фактора.

Сегодня ученым известно, что оксид азота обладает свойством управлять активностю иных медиаторов. В отношении гладкой мускулатуры сосудов оксид азота препятствует пролиферации клеток, а также регулирует процесс адгезии, поступающих к эндотелию лейкоцитов и тромбоцитов. Данное свойство обусловлено работой простациклина, который снижает образование тромбов и их адгезию. В том числе, данное вещество дезактивирует перемещение моноцитов, а также приводит в действие активатор плазминогена, имеет свойство вазорелаксирующей и антиоксидантной динамики, что позиционирует его как главный антиатеросклеротическим компонент.

Вещество ангиотензин II способствует образованию очагов липидной инфильтрации вызывает артериальных сосудов, что существенно снижает эффект оксида азота. Это происходит в силу того, что ангиотензин представляет собой сильнейший медиатор окислительного стресса, который провоцирует синтез цитокинов, что, в свою очередь, способствует началу воспалительного процесса на стенке сосуда. Когда начинается воспаление, ответным ударом является процесс синтеза ферментов поврежденными клетками эндотелия, в том числе, и выработка ангиотензинпревращающего фермента, принимающего непосредственное участие в производстве ангиотензина II, а также активирует разрушение брадикинина. Когда процесс работы брадикининовых рецепторов существенно снижен, то ослабляется интенсивность производства оксида азота. Ангиотензин II представляет собойстимулятор роста гладкомышечной ткани, провоцирующий синтез плазминогена и металлопротеиназа. Таким образом, брадикинин и ангиотензин II сопряжены с ангиотензинпревращающим ферментом, роль которого в прогнозировании пациентов с хронической сердечной недостаточностью, перенесших инфаркт миокарда велика, поскольку с его помощью образуется ангиотензин II, являющийся одним из основополагающих критериев сосудистого ремоделирования.

Изучая прогностическую значимость эндотелия, следует понимать многогранный сложный процесс взаимовлияния антагонистических медиаторов, которые обладают способностью регулирования многих физиологических критериев, касающихся процесса терапии больных с хронической сердечной недостаточностью. Данное свойство эндотелия связано с его гетерогенностью. а также о регуляции ими различных физиологических эффектов.

Клетки эндотелия отличаются своей неоднородностью. За прогнозирование процессов при хронической сердечной недостаточности у людей, перенесших инфаркт миокарда, отвечают коронарные клетки, которые обладают уникальными биохимическими признаками, специфическими рецепторами и составу белка, и отличаются от легочных, мозговых и других эндотелиальных клеток, следовательно, патологические признаки эндотелия у пациентов с хронической сердечной недостаточностью неодинаково в отношении заболеваний других органов. Нарушения в работе эндотелия имеет решающее значение в течении хронической сердечной недостаточности.

Патогенез хронической сердечной недостаточности напрямую связан с дисбалансом эндотелиальных факторов: увеличением степени влияния одних компонентов и снижения активности других веществ. Основополагающее прогностическое значение дисфункции эндотелия заключается в установлении наличия окислительного стресса, образования и цитокинов, которые в своей совокупности оказывают противодействующее влияние на нормальный синтез оксида азота.

На сегодняшний день не остаётся никаких сомнений В том, что дисфункция синтеза оксида азота является почвой для развития хронической сердечной недостаточности, которая образует глобальную проблему здравоохранения.

Посредством прогнозирования фармакологическим тестом с оценкой ситуации по вазомоторной функции сосудистого эндотелия и корреляционного анализа у больных с хронической сердечной недостаточностью, перенесших инфаркт миокарда выявлено: 
- усиление вазодилатации, снижении кровотока и интенсивности капиллярного кровотока у пациентов с хронической сердечной недостаточностью более выражено, чем у пациентов, не страдающих сердечно-сосудистыми заболеваниями. Степень этих состояний у пациентов с хронической сердечной недостаточностью в совокупности с небольшой интенсивностью выброса желудочка гораздо больше, что констатирует факт расстройства в работе вазомоторной функции сосудистого эндотелия у пациентов с хронической сердечной недостаточностью;

- корреляционная связь результатов фармакологического теста и состоянием интенсивности потока выброса левого желудочка, в том числе и в зависимости от возраста больного с хронической сердечной недостаточностью;

- у всех пациентов с хронической сердечной недостаточностью, при проведении тестирования В процессе усиления развития хронической сердечной недостаточности первой до третьей степени усиливается показатель вазодилатации, снижается интенсивность кровотока и снижается мощность капиллярного кровотока. Ассоциация утяжеления стадии хронической сердечной недостаточности и нарушений вазомоторной функции сосудистого эндотелия была также подтверждена результатами корреляционного анализа.

Из вышесказанного следует, что прогностическое значение дисфункции эндотелия велико, поскольку эндотелиальные клетки представляют собой основополагающие звенья цепи сердечно-сосудистого континуума. В настоящее время учеными доказано непосредственное участие эндотелия в диагностировании и прогнозировании артериальной гипертензии, атерогенезе, ишемии миокарда, образовании коронарного тромбоза, а также хронической сердечной недостаточности.

\section{2. Прогностическое значение миокарАиального фиброза \\ у ^юАей с хронической серАечной неАостаточностью, перенесших инФаркт миокарАа}

На сегодняшний день фиброзом миокарда называется патологический процесс, сущность которого заключается в излишнем отложении коллагена в миокарде, когда интенсивность образования этого вещества превышает скорость его распада. Особое негативное значение фиброз миокарда имеет для пациентов, перенесших инфаркт.

Долгое время под сердечной недостаточностью подразумевалось снижение сократительной функции миокарда, дилатация левого желудочка и снижение фракции выброса по данным ЭхоКГ. Однако в настоящее время в связи с увеличением продолжительности жизни и частоты развития артериальной гипертонии нарастает эпидемия сердечной недостаточности с сохраненной фракцией выброса, которая характеризуется нарушением диастолической функции левого желудочка, нормальными размерами левого желудочка и может сочетаться с гипертрофией миокарда. Но наличие гипертрофии при этом не является обязательным [5].

В основе диастолической сердечной недостаточности лежит диастолическая дисфункция, обусловленная снижением растяжимости желудочков при заполнении их кровью в диастолу, что вызывает повышение сократимости предсердий, перегрузку их объемом и в конечном счете приводит к развитию венозного полнокровия в малом круге кровообращения

Главным следствием фиброза выявлено уменьшение степени растяжимости желудочков. Это происходит из-за роста количества волокон коллагена, а также в следствие модификации его свойств. Примером таких изменений может служить смена положения волокон коллагена из продольной оси в горизонтальную, что способствует усилению жесткости миокарда.

В том числе, в гипертрофированном миокарде снижается количество эластичного коллагена третьего типа и повышается количество жесткого коллагена первого типа. Многие специалисты причисляют фиброзу миокарда грань бессимптомной дисфункции к диастолической сердечной недостаточности, это же касается и пациентов с хронической сердечной недостаточностью. С целью достижения снижения жесткости миокарда следует активировать реверсию фиброза.

В начале процесса формирования сердечные фибробласты образуются посредством деятельности мезенхимальных клеток, сосредоточенных в области венозного полюса сердца, далее они перемещаются по всей по поверхности, так происходит формирование эпикарда. В процессе образования эпикардиальных клеток происходит синтез фибробласты и миофибробласты. В тоге своих перемещений эти клетки приобретают фенотип фибробласта. Следует помнить, что их возможно реактивировать в миофибробласты, как процесс реакции на повреждение. В ходе постнатального процесса фибробласты преобразуются из группы эндотелиальных клеток, в том числе, из области костного мозга в ходе жизнедеятельности кроветворных клеток.

На сегодняшний день ученым не удалось выявить маркер фибробластов, попытки его установления не увенчались успехом, в руках исследователей имеют- 
ся лишь отличительные маркеры. К таковым относится клеточный поверхностный рецептор коллагена дискоидин, который можно обнаружить в фибробластах тканей сердца, и он не содержится в миоцитах, структурирующих гладкие клетки мышц сосудов, а также являются составляющей частью эндотелиальных клеток. Еще одним отличительным маркеров был выявлен специфический белок-1, но несколько позже было установлено, что его можно встретить и в иных группах клеток, что сделало его неэффективным показателем прогнозирования эндотелиального фиброза у пациентов с хронической сердечной недостаточностью, перенесших инфаркт миокарда. Данные клетки удалось также выявить в ишемических кардиомиоцитах, а также многих группах раковых клеткок.

Прогностические исследования состояния миокарда за последние несколько лет были существенно расширены. Посредством прогнозирования удалось проследить развитие фиброза и установить роль межклеточного (интерстициального) пространства, которое с течением исследовательской деятельности именовалось межклеточный матрикс. Несколько лет назад внеклеточное пространство исчисляли как объемную часть сердечной ткани, свободной от клеток (кардиомиоцитов). Данное пространство характеризовали как гистологическое образование, а гораздо позже, благодаря прогностическим исследованиям было установлено, что пространство способно изменяться и исчисляется как интегральный фактор динамического видоизменения, происходящего в зависимости от изменений внешний критериев в миокарде: механических, электрических и других.

Сердечные фибробласты, образованные без патологии, представляют собой плоские клетки, которые имеют веретенообразный вид и снабжены специфическими отростками. В свою очередь, эти отростки формируют целую сеть ячеек, расположенную в области внеклеточного матрикса. Данные цепочки способствуют тому, что фибропласты могут реагировать на различные внешние раздражители, в том числе, могут образовывать группы миоцитов, а также иных видов клеток в сердечной мышце. У фибробластов отсутствуют сократительные микрофиламенты, которые еще называют волокнами натяжения. Сконцентрированные движения фибробластов образуют секрецию различных сигнальных молекул, таких как цитокины и факторы роста.

Внеклеточный матрикс представляет собой макромолекулярную, метаболически подвижную сеть волокон, состоящих в основном из коллагеновых, а также клеток, представленных фибробластами, изменяющихся в миофибробласты, что играет важнейшую роль в нормальной работе сердечной мышцы.
Эти клетки окружают и инфильтруют внеклеточное пространство, при этом они связаны коллагеновыми волокнами, поэтому обладают свойством реагировать на механическое растяжение, либо давление, в том числе, аутокринные и паракриннные реакции модификации пролиферации, перемещения и скорости образования коллагена. Данные процессы могут приводить к ремоделированию сердца, что оказывает особенно пагубное влияние у пациентов с хронической сердечной недостаточностью, перенесших инфаркт миокарда. В этом случае своевременные прогностические исследования способны оказать неоценимую услугу болеющему и назначить адекватную терапию [4].

В эмбриональном периоде сердечные фибробласты главным образом происходят из мезенхимальных клеток-предшественниц, которые образуются вблизи венозного полюса сердца и затем, мигрируя по поверхности сердца, преобразуются в эпикард. В ходе развития из эпикардиальных клеток могут поочередно развиваться фибробласты и миофибробласты. В конечном счете большинство этих клеток принимает фенотип фибробласта, тем не менее они могут быть реактивированы в миофибробласты в ответ на повреждение. В постнатальном периоде фибробласты происходят из популяции эндоте-лиальных клеток вследствие эпителиально-мезенхимальной трансформации, а также в костном мозге из кроветворных клеток-предшественниц.

Волокна коллагена образуют структурный каркас миокарда. Они переплетаются в сложную трехмерную сеть, которая обеспечивает поддержку кардиомиоцитов на протяжении всего сердечного цикла и способствует трансформации сокращений отдельных клеток в единый силовой вектор. Эта сеть окружает как кардиомиоциты, так и фибробласты. Такое расположение сохраняет непрерывность в различных слоях стенки миокарда. Наряду с этим, образованная сеть выступает в качестве интегрального датчика динамического изменения при различных механических, химических и электрических стимулах, воздействующих на миокард. В ответ на эти стимулы эта сложная сеть регулирует продукцию внеклеточного матрикса и гипертрофию кардиомиоцитов и в меньшей степени - пролиферацию кардиомиоцитов, кроме того, она вызывает активацию фиброзных и воспалительных процессов. Следует отметить, что в зависимости от окружающей микросреды формируются различные фенотипы сердечных фибробластов.

Важным событием в развитии фиброза сердца является превращение фибробластов в миофибробласты, которые характеризуются в два раза большей способностью синтезировать коллаген, они более чувствительны к про-воспалительным и профибротическим стимулам 
и способны синтезировать большее количество разнообразных цитокинов и хемокинов.

Ядерные микрорибонуклеиновые кислоты (микро-РНК) играют важную регулирующую роль в ремоделиро-вании сердца и оказываются вовлеченными в большую часть биологических процессов. Они относятся к эндогенным одноцепочечным коротким некодируемым рибонуклеиновым кислотам длиной 18-25 нуклеотидов, которые принимают участие в регуляции экспрессии генов. Микро-РНК ухудшает или ингибирует перевод рибонуклеиновых кислот на посттранскрипционный уровень, регулируя тем самым экспрессию генов [4].

В условиях течения хронической сердечной недостаточности окислительный стресс также модифицируется в хроническую форму, что провоцирует субклиническое воспаление, активируя процесс образования фиброза миокарда.

Данные процессы способствуют уменьшению теломер, нарушению структуры дезоксирибонуклеиновой кислоты, клеточной гибели кардиомиоцитов, затруднению способности организма к восстановительным реакциям после полученных повреждений в результате инфаркта миокарда.

В настоящее время уже начато прогнозирование сывороточных маркеров производства и разрушения миокардиального коллагена. На сегодняшний день выполнено большое количество научных работ по исследованию количества биомаркеров коллагена в крови у пациентов с хронической сердечной недостаточностью, перенесших инфаркт миокарда. В части проведенных испытаний было установлено наличие изменений одного или двух маркеров, что говорит о том, что для получения более точных прогнозов необходимо комбинировать маркеры для отслеживания количества коллагена.

Более всего в рамках современного прогнозирования удалось изучить С-концевой пропептид проколлагена типа I, С-концевой телопептид коллагена типа I, матриксная металлопротеиназа I и тканевой ингибитор матриксных металлопротеиназ-1. Проведенные исследования позволяют изучить регуляцию этих веществ, установить из наличие и провести количественный анализ, однако, необходимо помнить, что данный способ изучения биомаркеров носит характер тестирования и не может выдать детальную картину прогноза содержания этих веществ. Поэтому поставить диагноз состояния сердца у больных с хронической сердечной недостаточностью, перенесших инфаркт миокарда, крайне затруднительно, результат будет иметь предположительный характер. Однако при всей привлекательности использования маркеров коллагена для оценки фиброза не стоит забывать, что это всего лишь лабораторный тест, и любое заключение о состоянии пациента не даст развёрнутой картины течения заболевания. Лабораторные тесты в значительной мере уступают наглядным приёмам исследования в отношении точности прогнозирования фиброза миокарда.

Измерение внеклеточного объема в ходе проведения МРТ с контрастированием позволяет определить пространство, которое занимает внеклеточный матрикс, что является полезной суррогатной точкой. У определения внеклеточного объема имеется надежное гистологическое подтверждение, он коррелирует с объемной долей коллагена. Этот новый параметр является важным потому, что фиброз миокарда является повсеместным и связан с ремоделированием миокарда. При отсутствии амилоидоза и инфильтративных заболеваний, а также клинических условий, которые способствовали отеку миокарда, внеклеточный объем, определенный при MPT, является биомаркером фиброза миокарда.

Определение внеклеточного объема отражает объемную долю сердечной ткани, которая не занята клетками. Для его определения используется контрастирование с гадолинием. Внеклеточный объем определяют путем совмещения пиксельных карт определения Т1 до и после контрастирования с поправкой на уровень гематокрита.

По современным представлениям, фибробласт является основной клеткой, ответственной за поддержание гомеостаза внеклеточного матрикса в миокарде. Такие патологические процессы, как дилатация или гипертрофия камер сердца, способствуют трансформации фибробласта в миофибробласт, непосредственно участвующий в формировании миокардиального фиброза и в конечном итоге хронической сердечной недостаточности.

\section{Выво $\triangle \mathrm{b}$}

У пациентов с хронической сердечной недостаточностью, перенесших инфаркт миокарда, происходит существенное ослабление антитромбогенной и вазодилатирующей активности сосудистой стенки. Эндотелий обладает свойством гетерогенности, с работой которого связаны все критерии развития хронической сердечной недостаточности у пациентов, перенесших инфаркт миокарда. Вазодилатирующее свойство эндотелия заключается в регулировании производства оксида азота, простациклина и эндотелиального гиперполяризующего фактора.

Установление баланса работы факторов вазоконстрикторов, синтеза цитокинов, окислительного стресса 
и образованием оксида азота у таких пациентов имеет решающее значение, поскольку данные процессы регулируют физиологические эффекты протекания хронической сердечной недостаточности.

Миокардиальный фиброз представляет собой опаснейший и сложный патологический процесс, который может сопровождать различные формы хронической сердечной недостаточности и видится как глобальная многогранная проблема здравоохранения, требующая детального ее изучения и прогнозирования течения заболеваний, связанных с хронической сердечной недостаточностью. Особое угрожающее значение этот вид патологии имеет для пациентов, перенесших инфаркт миокарда.

Образование фиброза миокарда может прогрессировать достаточно быстро, что крайне пагубно повлияет на весь процесс течения сердечной недостаточности. Еще одним основополагающим негативным фактором терапии пациентов миокардиальным фиброзом являет- ся неполное знание роли фибробластов, что затрудняет прогнозирование и последующей терапии этого опасного заболевания, что существенно тормозит план лечения таких пациентов и оказание воздействия на данный тип клеток, посредством которого удастся приостановить их прогрессирующий процесс. Следует отметить, что имеющиеся знания и опыт работы в терапии миокардиального фиброза помогают специалистам в поисках путей адекватной терапии, при помощи которой можно добиться снижения выраженности миокардиального фиброза.

Своевременное и качественное прогнозирование дисфункции эндотелия и миокардиального фиброза способствует установлению адекватной терапии людей с хронической сердечной недостаточностью, перенесших инфаркт миокарда, что существенно продлит жизнь пациентов и сделает их жизнедеятельность наиболее благоприятной в условиях протекания вышеуказанных заболеваний.

\section{ЛИТЕРАТУРА}

1. Арболишвили Г.Н. Связь показателей вариабельности ритма сердца с механизмом смерти больных с хронической сердечной недостаточностью// Сердечная недостаточность, 2018. С. 172-179

2. Сторожаков Г.И., Эндотелиальная дисфункция при сердечной недостаточности. Клиническая геронтология, 2016. - 315 с.

3. Коркушко 0.В., Лишневская В.Ю. Эндотелиальная дисфункция. Кровообращение и гемостаз, 2016. - 426 с

4. Хежева Ф.М., Мазур Н.А. Сывороточные маркеры фиброза у больных артериальной гипертонией. Кардиология, 2016. - С. 64-69

5. Travers JG, Kamal FA, Robbins J et al. Cardiac Fibrosis: The Fibroblast Awakens. Circ Res, 2016. —P. 37-42 